\title{
Ventricular arrhythmias in long term survivors of orthotopic and heterotopic cardiac transplantation
}

\author{
DIMITRIOS ALEXOPOULOS, $\ddagger$ SALIM YUSUF, $\S$ JULIAN BOSTOCK, $\dagger$ \\ JIM A JOHNSTON, * PETER SLEIGHT, * MAGDI H YACOUB $\dagger$
}

From $\dagger$ Harefield Hospital, Harefield, Middlesex and the John Radcliffe Hospital, Oxford

SUMMARY Fourteen long term survivors with orthotopic (recipient heart replaced by donor heart) and nine with heterotopic cardiac transplants (recipient heart retained) had 24 hour ambulatory electrocardiographic monitoring to detect ventricular arrhythmias. Arrhythmia was uncommon in the patients with orthotopic transplants; none of them had more than one extrasystole per hour. In $\frac{1}{\infty}$ the patients with heterotopic cardiac transplants the recipient's own heart showed significantly $\bigcirc$ more frequent ventricular arrhythmias than the corresponding donor heart: abnormal complexes (mean/24 h) 4583 vs 42.7; extrasystoles 1772 vs $17 \cdot 8$; pairs 121 vs 0.8 . There was no relation between the abnormal ventricular activity of the two hearts in the patients with heterotopic transplants on a beat by beat, hourly, or 24 hour basis. There was no consistent diurnal variation in $\vec{\oplus}$ the frequency of the abnormal ventricular beats after cardiac transplantation. The occurrence of $\infty$ ventricular arrhythmia was unrelated to the interval from operation to the study.

In long term survivors of cardiac transplantation the denervated heart shows a little ventricular ectopic activity even when compared with normal hearts. In patients with heterotopic transplants ventricular arrhythmias commonly occur in the recipient's own heart; these are probably related to the underlying severity of the original disease.

Ventricular arrhythmias during ambulatory monitoring have been reported to be more frequent in patients after conventional orthotopic cardiac transplantation than in normal subjects..$^{1-3}$ Most of these arrhythmias occur soon after the operation. ${ }^{4}$ Little is known about their occurrence, possible causes, and potential influence on prognosis in late survivors of cardiac transplantation. ${ }^{5}$

The development of two channel electrocardiographic recorders and computerised analysers permits the separate identification of the QRS complexes of the two hearts (donor and recipient) after heterotopic cardiac transplantation and a quantitative simultaneous study of the ventricular arrhythmias of both hearts during Holter monitoring.

The purpose of our study was to (a) find out how common ventricular arrhythmia was in the den-

Requests for reprints to Magdi H Yacoub, FRCS, Harefield Hospital, Harefield, Middlesex UB9 6JH.

Present addresses: $₫$ Mount Sinai Medical Center, 1 Gustave L Levy Place, New York, NY 10029; §216 Federal Building, National Heart, Lung, and Blood Institute, Bethesda, MD 20892, USA.

Accepted for publication 15 December 1987 ervated heart late after transplantation, $(b)$ to assess whether ventricular arrhythmia was more common after heterotopic transplantation than after orth otopic transplantation, and (c) to compare the occurrence of ventricular arrhythmia in the denervated donor and innervated recipient hearts in patients with heterotopic transplants.

\section{Patients and methods}

Fourteen men with orthotopic (mean (SD) age 45 (8) years) and nine patients with heterotopic (eight men and one woman, age $42(10)$ years) cardiac transplants $N$ were studied by ambulatory 24 hour electrocar- $N$ diographic monitoring. Donor hearts were obtained $\stackrel{\sim}{\mathcal{C}}$ from individuals aged 22 (7) years. The surgical $\omega$ techniques are described elsewhere. ${ }^{67}$ The interval from operation to the study varied from six to 42 months (mean 20) in the orthotopic and from seven to 18 months (mean 11) in the heterotopic transplantation group. Most of the patients were taking a mixture of drugs (cyclosporin, azathioprine, prednisolone, aspirin, dipyridamole, and diuretic) but no patient was on an antiarrhythmic drug. All patients were symptom free, ambulant, and performing their 

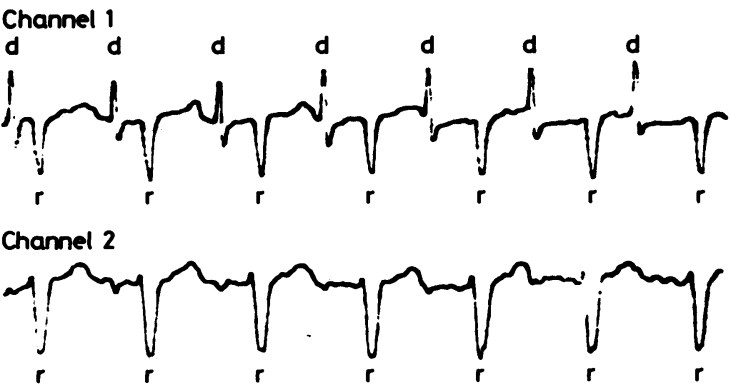

Fig 1 Typical electrocardiographic trace from 24 hour Holter monitoring of a patient with a heterotopic cardiac transplant. Channel 1: donor's (d) and recipient's (r) QRS complexes are clearly distinguishable. Channel 2: recipient's (r) QRS complex is dominant.

usual daily activities. Each patient kept a detailed diary of activity and symptoms. The most recent biopsy specimen was normal in 21 patients but two patients showed evidence of mild rejection.

\section{ELECTROCARDIOGRAPHIC RECORDING}

Ambulatory 24 hour electrocardiograms were recorded on Oxford Medilog II recorders with two channels. The skin was carefully prepared and electrodes were placed to record modified lead V1 and V4 in patients with orthotopic transplants. In patients with heterotopic transplants a modified V4R lead was recorded instead of $\mathrm{V} 1$ to permit better separation of the two QRS complexes. Because the donor heart lay to the right of the recipient heart its QRS complex was clearly delineated in V4R whereas in lead V4 the QRS complex of the recipient's own heart was dominant. Figure 1 shows a typical electrocardiographic trace from a patient with a heterotopic cardiac transplant.

\section{ARRHYTHMIA ANALYSIS}

We used a computerised template system (J Johnston, Oxford), based on a QRS pattern recognition that could classify QRS complexes into different families, to analyse the ventricular arrhythmias. The system consisted of a Z80A pre-processor and a DEC LSI-11 master. The normal QRS complex was defined by the operator and recognised by the system thereafter. Any unrecognised QRS complex was screened carefully by the operator and if its shape indicated a ventricular origin or abnormal ventricular conduction it was classified and subsequently recognised as an "abnormal complex". We used the following definitions: extrasystole, an abnormal complex with a coupling interval less than $80 \%$ of the previous RR interval; pair, two consecutive abnormal complexes; run, three or more abnormal com- plexes with a rate less than 120 per minute; ventricular tachycardia, three or more ventricular extrasystoles with a rate greater than 120 per minute. Figure 2 shows an example of ventricular extrasystoles from the donor and the recipient heart of a patient with a heterotopic transplant.

Every electrocardiographic tape from the group with heterotopic transplants was analysed twice and the dominant QRS complex on each channel was identified separately. In the heterotopic transplant group we attempted to correlate the frequency of the abnormal complexes and ventricular extrasystoles in the two hearts during the whole 24 hour period and also on an hourly basis. In addition, we attempted to study the possible temporal relation between individual extrasystoles in the two hearts.

The times of waking up and sleeping were noted and the mean rates of abnormal complexes and extrasystoles during sleep and wakefulness were calculated in both groups.

Finally, in both groups we examined the severity of arrhythmia and the interval since operation to see whether there was a correlation.

\section{STATISTICAL ANALYSIS}

All data are expressed as mean values (1 SD). We used the paired or unpaired Student's $t$ test and the non-parametric Wilcoxon test as appropriate.

\section{Results}

\section{CLINICAL CHARACTERISTICS}

Not surprisingly, the donor hearts were obtained from individuals who were younger than the recipients $(p<0.001)$. The ages of the donors and

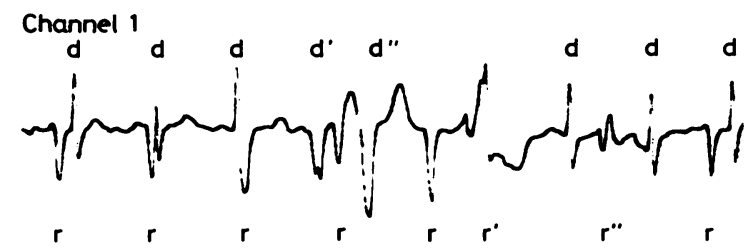

Channel 2

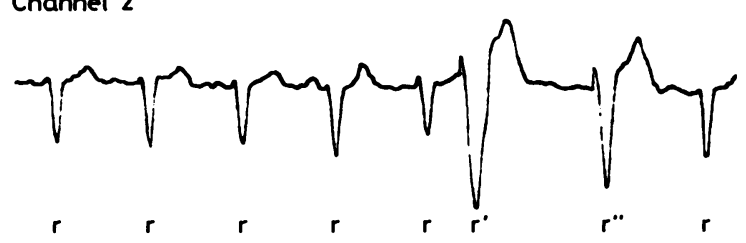

Fig 2 Electrocardiographic trace of a patient with heterotopic cardiac transplantation with extrasystoles from both hearts. Channel 1: donor's (d) QRS complex is dominant. Channel 2: recipient's ( $r$ ) QRS complex is dominant. $d^{\prime}$ and $d^{\prime \prime}$, extrasystoles from donor's heart. $r^{\prime}$ and $r^{\prime \prime}$, extrasystoles from recipient's heart. 
the recipients in the orthotopic and heterotopic transplant groups were not significantly different. The mean interval from operation to the study was longer in the orthotopic group than the heterotopic transplantation group $(\mathrm{p}<0.02)$.

No symptoms were reported by patients during the 24 hour study period.

\section{ARRHYTHMIAS}

Tables 1 and 2 shows the number of the "abnormal complexes", extrasystoles, pairs, and runs in the two groups of patients. Ventricular tachycardia was not seen in any patient. Nine $(39 \%)$ out of the 23 denervated hearts had no abnormal ventricular activity at all and in rest such activity was infrequent. This low occurrence of ventricular arrhythmia was similar in the donor hearts of both groups. We saw many abnormal complexes and extrasystoles in the recipient hearts of those patients with heterotopic transplants.

Analysis of the arrhythmia frequency in those with heterotopic transplants on a 24 hour or hourly basis showed no relation between the two hearts. The occurrence of an extrasystole in the one heart did not correlate with the presence of an extrasystole in the other heart.

Table 3 shows the frequency of abnormal complexes per hour during sleep and waking. Abnormal complexes were less common during sleep in four donor and two recipient hearts in the nine patients with heterotopic transplants. In the orthotopic group three of the eight patients with abnormal ventricular activity showed a decline in the frequency during sleep. The occurrence of extrasystoles during the $\mathbf{2 4}$ hour period was also reduced during sleep.

Finally, the occurrence of abnormal complexes or ventricular extrasystoles was unrelated to the time since operation in both the orthotopic and heterotopic groups.
Table 1 Complexes with abnormal $Q R S$ shape and ventricular arrhythmias detected during 24 hour monitoring in patients with orthotopic cardiac transplants

\begin{tabular}{lllll}
\hline No & $\begin{array}{l}\text { Abnormal } \\
\text { complexes }\end{array}$ & Extrasystoles & Pairs & Runs \\
\hline 1 & 0 & 0 & 0 & 0 \\
2 & 5 & 2 & 0 & 0 \\
3 & 0 & 0 & 0 & 0 \\
4 & 21 & 19 & 1 & 0 \\
5 & 9 & 9 & 0 & 0 \\
6 & 0 & 0 & 0 & 0 \\
7 & 9 & 9 & 0 & 0 \\
8 & 0 & 0 & 0 & 0 \\
9 & 3 & 2 & 0 & 0 \\
10 & 1 & 1 & 0 & 0 \\
11 & 1 & 3 & 0 & 0 \\
12 & 0 & 0 & 0 & 0 \\
13 & 0 & 0 & 0 & 0 \\
14 & 29 & 6 & 2 & 1 \\
Mean & $5 \cdot 9$ & $3 \cdot 6$ & $0 \cdot 3$ & $0 \cdot 1$ \\
\hline
\end{tabular}

\section{Discussion}

We are unaware of any previous reports of Holter monitoring of ventricular arrhythmias in patients with heterotopic cardiac transplants. This is perhaps because patients with this type of cardiac transplantation (where the original heart is retained) are rare and it is difficult to separate the QRS complexes of the two hearts during ambulatory monitoring. We found that the occurrence of ventricular arrhythmias was similar in the donor hearts of patients with orthotopic and heterotopic transplantation, so differences in surgical technique and haemodynamic function do not seem to influence significantly the occurrence of ventricular arrhythmia. In contrast, the recipient hearts of the heterotopic transplantation group showed substantially greater ventricular arrhythmia, probably because of contributory factors such as the presence of severe coronary or myocardial disease, possible dysfunction of the autonomic regulatory pathways, ${ }^{8-10}$ and surgical trauma.

Table 2 Complexes with abnormal QRS shape and ventricular arrhythmias detected during 24 hour monitoring in patients with heterotopic cardiac transplants

\begin{tabular}{|c|c|c|c|c|c|c|c|c|}
\hline \multirow[b]{2}{*}{ No } & \multicolumn{4}{|c|}{ Donor heart } & \multicolumn{4}{|c|}{ Recipient heart } \\
\hline & $\begin{array}{l}\text { Abnormal } \\
\text { complexes }\end{array}$ & Extrasystoles & Pairs & Runs & $\begin{array}{l}\text { Abnormal } \\
\text { beats }\end{array}$ & Extrasystoles & Pairs & Runs \\
\hline $\begin{array}{l}1 \\
2 \\
3 \\
4 \\
5 \\
6 \\
7 \\
8 \\
9 \\
\text { Mean }\end{array}$ & $\begin{array}{c}20 \\
0 \\
4 \\
8 \\
0 \\
0 \\
11 \\
4 \\
337 \\
42 \cdot 7\end{array}$ & $\begin{array}{c}20 \\
0 \\
4 \\
8 \\
0 \\
0 \\
11 \\
2 \\
115 \\
17 \cdot 8\end{array}$ & $\begin{array}{l}4 \\
0 \\
0 \\
0 \\
0 \\
0 \\
3 \\
0 \\
0 \\
0.8\end{array}$ & $\begin{array}{l}0 \\
0 \\
0 \\
0 \\
0 \\
0 \\
0 \\
0 \\
0\end{array}$ & $\begin{array}{r}14608 \\
2337 \\
41 \\
18 \\
19 \\
222 \\
2658 \\
25 \\
11317 \\
4583 \dagger\end{array}$ & $\begin{array}{r}3421 \\
860 \\
35 \\
18 \\
17 \\
200 \\
7599 \\
13 \\
3788 \\
1772 \dagger\end{array}$ & $\begin{array}{r}410 \\
23 \\
6 \\
2 \\
0 \\
0 \\
90 \\
0 \\
563 \\
121 \star\end{array}$ & $\begin{array}{r}241 \\
0 \\
0 \\
2 \\
0 \\
0 \\
91 \\
0 \\
318\end{array}$ \\
\hline
\end{tabular}

Compared with the donor heart: ${ }^{\star} \mathrm{p}<0.05 .+\mathrm{p}<0.01$. 
Table 3 Number of abnormal complexes per hour while patients were awake and asleep

\begin{tabular}{|c|c|c|c|c|c|c|c|}
\hline \multicolumn{5}{|c|}{ Heterotopic } & \multicolumn{3}{|c|}{ Orthotopic } \\
\hline \multirow{2}{*}{$\begin{array}{l}\text { No of } \\
\text { patient }\end{array}$} & \multicolumn{2}{|l|}{ Donor } & \multicolumn{2}{|c|}{ Recipient } & \multirow{2}{*}{$\begin{array}{l}\text { No of } \\
\text { patient }\end{array}$} & \multicolumn{2}{|l|}{ Donor } \\
\hline & Awake & Asleep & Awake & Asleep & & Awake & Asleep \\
\hline $\begin{array}{l}1 \\
2 \\
3 \\
4 \\
5 \\
6 \\
7 \\
8 \\
9\end{array}$ & $\begin{array}{l}1 \cdot 3 \\
0 \\
0 \cdot 1 \\
0 \cdot 4 \\
0 \\
0 \\
0 \cdot 6 \\
0 \cdot 3 \\
7 \cdot 2\end{array}$ & $\begin{array}{l}0 \cdot 1 \\
0 \\
0 \cdot 5 \\
0 \\
0 \\
0 \\
0 \cdot 2 \\
0 \\
27\end{array}$ & $\begin{array}{c}256 \\
115 \\
1 \cdot 9 \\
0 \cdot 4 \\
0 \cdot 9 \\
7 \cdot 2 \\
328 \\
1 \cdot 2 \\
687\end{array}$ & $\begin{array}{c}1302 \\
69 \\
1 \cdot 7 \\
1 \cdot 7 \\
0 \cdot 9 \\
12 \cdot 8 \\
845 \\
1 \\
40\end{array}$ & $\begin{array}{r}2 \\
4 \\
5 \\
7 \\
9 \\
10 \\
11 \\
14\end{array}$ & $\begin{array}{l}0 \cdot 1 \\
1 \cdot 1 \\
0 \cdot 2 \\
0 \cdot 3 \\
0 \cdot 1 \\
0 \\
0 \cdot 3 \\
1 \cdot 7\end{array}$ & $\begin{array}{l}0 \cdot 4 \\
0 \cdot 6 \\
0 \cdot 8 \\
0 \cdot 3 \\
0 \\
0 \cdot 1 \\
0 \\
0 \cdot 7\end{array}$ \\
\hline
\end{tabular}

Ventricular arrhythmias were uncommon in the denervated transplanted heart; they were no more common than in normal individuals. ${ }^{11-13}$ Only one denervated heart in this series showed more than a hundred extrasystoles in 24 hours; again this is probably within normal limits. The infrequent occurrence of ventricular arrhythmias during continuous ambulatory electrocardiographic monitoring in patients after orthotopic cardiac transplantation accords with previous studies, ${ }^{114}$ although in these patients arrhythmias were less vigorously measured.

Several factors may be implicated in the arrhythmogenesis after cardiac transplantation. Supersensitivity to circulating catecholamines, ${ }^{15}$ rejection episodes, and accelerated atherosclerosis ${ }^{16}$ could favour the production of arrhythmia in the donor heart. But the low frequency of extrasystoles implies that such factors have a limited role. In the innervated hearts of the heterotopic group severe underlying disease (coronary artery disease, congestive cardiomyopathy) is the most likely cause for the increased numbers of arrhythmias. The lack of correlation between the arrhythmia in the donor and recipient heart underscores the importance of the different aetiological factors causing extrasystoles. In addition, the absence of simultaneous occurrence of arrhythmia indicates either lack of effect of the stimuli common for both hearts, such as hormonal factors and physical activity, or different bases for these stimuli in each heart.

Unlike normal subjects ${ }^{17}$ we found no overall reduction in extrasystoles during sleep. Denervation of the donors' hearts and autonomic dysfunction ${ }^{12-14}$ of the severely diseased recipient's own hearts might be responsible for the absence of a diurnal variation. It was interesting that some of the denervated donor hearts did show a reduction in extrasystoles during sleep; this probably reflects the lowered plasma catecholamines seen during sleep, with perhaps some added amplification caused by denervation supersensitivity.
Despite the frequent occurrence of extrasystoles in the recipient heart our patients did not report dizziness or palpitations. This presumably reflected the relatively small contribution of the recipient heart to total cardiac output.

Our study is limited by the short duration ( 24 hours) of electrocardiographic monitoring, since there is a significant day to day variability in the frequency of extrasystoles in patients with innervated hearts ${ }^{18}$; there is no information on such variability after cardiac denervation. The generally low occurrence of arrhythmia suggests that there will be less day to day variation in counts.

In conclusion, ventricular arrhythmias were no more common in donor hearts than in normal individuals. In contrast, the very high occurrence of ventricular extrasystoles in recipient hearts was probably related to their underlying severe disease. There was no evidence of simultaneous arrhythmia in both recipient and donor hearts.

\section{References}

1 Berke DK, Graham AF, Schroeder JS, Harrison DC. Arrhythmias in the denervated transplanted heart. Circulation 1973;47-48(suppl III):112-5.

2 Harrison DC, Mason JW, Schroeder JS, Stinson EB Effects of cardiac denervation on cardiac arrhythmias and electrophysiology. $\mathrm{Br}$ Heart $J$ 1978;40(suppl): 17-23.

3 Mason JW, Stinson EB, Harrison DC. Autonomic nervous system and arrhythmias: studies in the transplanted denervated human heart. Cardiology 1976; 61:75-87.

4 Schroeder JS, Berke DK, Graham AF, Rider AK, Harrison DC. Arrhythmias after cardiac transplantation. Am J Cardiol 1974;33:604-7.

5 Romhilt DW, Doyle MRN, Sayar KB, et al. Prevalence and significance of arrhythmias in long-term survivors of cardiac transplantation. Circulation 1982;66(suppl I):219-22.

6 Stinson EB, Dong E Jr, Iben AB, Shumway NE. 
Cardiac transplantation in man. III Surgical aspects. Am J Surg 1969;118:182-7.

7 Yusuf S, Mitchell A, Yacoub MH. Interrelation between donor and recipient heart rates during exercise after heterotopic cardiac transplantation. Br Heart $\mathrm{J}$ 1985;54:173-8.

8 Eckberg DL, Drabinsky M, Braunwald E. Defective cardiac parasympathetic control in patients with heart disease. N Engl J Med 1971;285:877-83.

9 Covell JW, Chidsey CA, Braunwald E. Reduction of the cardiac response to postganglionic sympathetic nerve stimulation in experimental heart failure. Circ Res 1966;19:51-6.

10 Gaffney TE, Braunwald E. Importance of the adrenergic nervous system in the support of circulatory function in patients with congestive heart failure. $\mathrm{Am}$ J Med 1983;34:320-4.

11 Kostis JB, McCrone K, Moreyra AE, et al. Premature ventricular complexes in the absence of identifiable heart disease. Circulation 1981;63:1351-6.

12 Brodsky M, Wu D, Denes P, Kanakis C, Rosen KM. Arrhythmias documented by 24 hour continuous electrocardiographic monitoring in $\mathbf{5 0}$ male medical students without apparent heart disease. $A m ~ J$
Cardiol 1977;39:390-5.

13 Sobotka PA, Mayer JH, Bauernfeind RA, Kanakis C Jrf. Rosen KM. Arrhythmias documented by 24 hour continuous ambulatory electrocardiographic mon $\stackrel{5}{?}$ itoring in young women without apparent hear disease. Am Heart $J$ 1981;101:753-9.

14 Bexton RS. Electrophysiology of the transplanted human heart. Oxford University, 1983. MD thesis. $\mathbb{D}$

15 Yusuf S, Theodoropoulos S, Mathias CJ, et al Increased sensitivity of the denervated transplanted"s human heart to isoprenaline both before and after beta-blockade. Circulation 1987;75:697-704.

16 Uretsky BF, Murali S, Reddy PS, et al. Development of coronary artery disease in cardiac transplant patients receiving immunosuppressive therapy with cyclo- $-\frac{7}{\square}$ sporine and prednisone. Circulation 1987;76:827-34.

17 Lown B, Tykocinski M, Garfein A, Brooks P. Sleepo and ventricular premature beats. Circulations 1973;48:691-701.

18 Morganroth J, Michelson EL, Horowitz LN, Joseph-o son ME, Pearlman AS, Dunkman WB. Limitations of routine long-term electrocardiographic monitoring to assess ventricular ectopic frequency. Circulations 1978;58:408-14. 